\title{
Research Paper \\ The Effectiveness of Cognitive-Behavioral Training in Decreasing the Punitive Behavior of Mothers of Students with Intellectual Disability
}

\author{
Hossein Akbarifar ${ }^{* 1}$, Parviz Sharifi Daramadi², Shahla Pezeshk ${ }^{3}$ \\ 1. Ph.D. Student of Psychology of Children and Adolescents with Special Needs, Faculty of Psychology and Educational Sciences, \\ Allameh Tabataba'i University, Tehran, Iran \\ 2. Professor, Department of Psychology of Children and Adolescents with Special Needs, Faculty of Psychology and Educational \\ Sciences, Allameh Tabataba'i University, Tehran, Iran \\ 3. Associate Professor, Department of Psychology of Children and Adolescents with Special Needs, Faculty of Psychology and \\ Educational Sciences, Allameh Tabataba'i University, Tehran, Iran
}

Citation: Akbarifar H, Sharifi Daramadi P, Pezeshk S. The effectiveness of cognitive-behavioral training in decreasing the punitive behavior of mothers of students with intellectual disability. Quarterly Journal of Child Mental Health. 2020; 7(3): 182-192.

\section{http://dx.doi.org/10.52547/jemh.7.3.15}

\section{A R T I C L E I N F O}

\section{Keywords:}

Cognitive-Behavioral

training,

punitive behavior,

mothers,

students with intellectual

disability

Received: 16 Mar 2019

Accepted: 15 Sep 2020

Available: 7 Dec 2020

\section{A B S T R A C T}

Background and Purpose: Having a child with disability or disease in the family causes a great deal of stress for parents, especially for mothers, because they may experience more stress, feeling of guilt, and fatigue compared to other parents. The present study aimed at investigating the effectiveness of cognitive-behavioral training on decreasing the punitive behavior in the mothers of students with intellectual disability.

Method: This research was an experimental study with control group pretest-posttest design. The study population included the mothers of all primary school students with intellectual disability in Shadgan city in the academic year of 2014-2015 (i.e. 90 mothers in total). Based on inclusion and exclusion criteria, 20 mothers were selected as the sample and then randomly placed into the experimental or control group. Sessions of cognitive-behavioral training was conducted for the experimental group, while no training was done for the control group. Data were collected by Punishment Questionnaire (Malekpour, 1997) and clinical interview. Analysis of covariance was used to analyze the data.

Results: Results of data analysis showed that cognitive-behavioral training significantly decreased the punitive behavior in the mothers of students with intellectual disability, in such a way that mothers in the experimental group showed significantly less punitive behavior than mothers in the control group at the posttest phase $(\mathrm{P}=0.001, \mathrm{~F}=539.494)$.

Conclusion: Based on the results of the present study, cognitive-behavioral training can be used as an accepted method to solve the psychological problems of parents and to reduce the punitive behavior in the mothers of students with intellectual disability.

\footnotetext{
* Corresponding author: Hossein Akbarifar, Ph.D. Student of Psychology of Children and Adolescents with Special Needs, Faculty of Psychology and Educational Sciences, Allameh Tabataba'i University, Tehran, Iran.

E-mail addresses: Akbarihossin@yahoo.com
} 


\section{اثربخشى آموزش برنامه شناختى - رفتارى بر كاهش رفتار تنبيهى مادران دانش آموزان كمثوان ذهنى

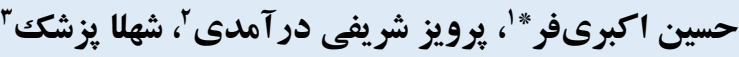

ا. دانشجوى دكتر اى روانشناسى كود كان و نوجوانان با نيازهاى ويثزه، دانشكده روانشناسى و علوم تربيتى، دانشگاه علامه طباطبائى، تهران، ايران

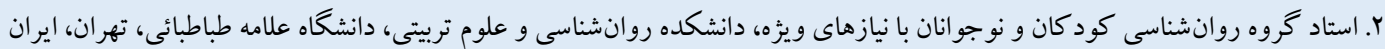

r. دانشيار گروه روانشناسى كود كان و نوجو انان با نيازهاى ويزه، دانشكده روانشناسى و علوم تربيتى، دانشگاه علامه طباطبايى، تهران، ايران

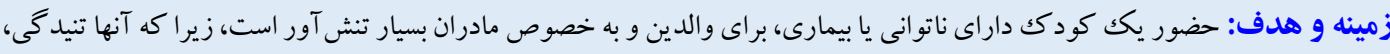

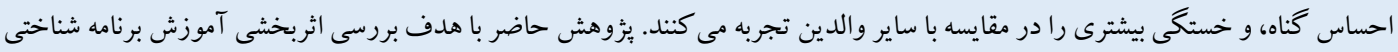
رفتارى بر كاهش رفتار تنبهى مادران دانش آموزان كمتوان ذهنى انجام شد.

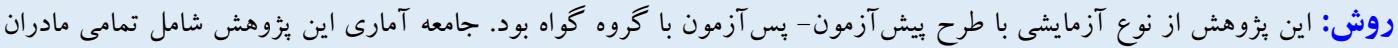

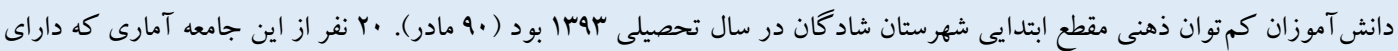

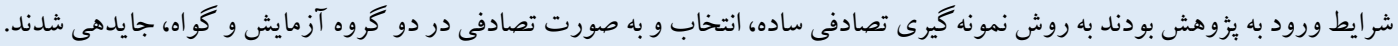

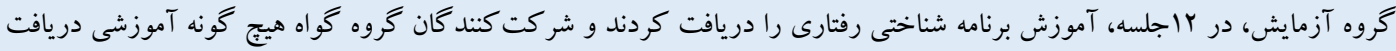

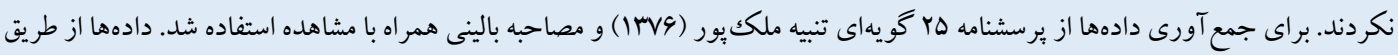
آزمون آمارى كوواريانس مورد تجزيه و تحليل قرار كرفت.

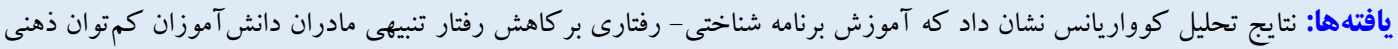

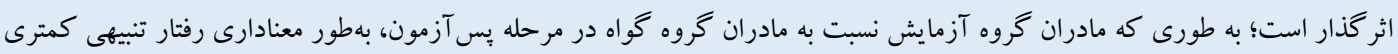

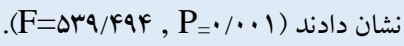

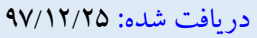
نتيجه كيرى: بر اساس نتايج يُزوهش حاضر، آموزش برنامه شناختى - رفتارى به عنو ان يك شيوه مورد تأييد براى كمك به مسائل و مشكلات

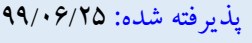

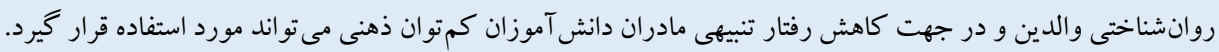

*ُ نويسنده مسئول: حسين اكبرىفر، دانشجوى دكتراى روانشناسى كود كان و نوجوانان با نيازهاى ويزٔه، دانشكده روانشناسى و علوم تربيتى، دانشكاه علامه طباطبائى، تهران، ايران. رايانامه: Akbarihossin@yahoo.com

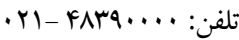


بِذيرش، احساسات منفى، سلامتى و ناسلامتى مادر و عدم تو انمندى مادر

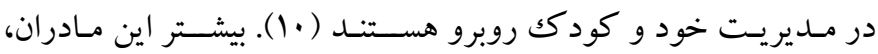

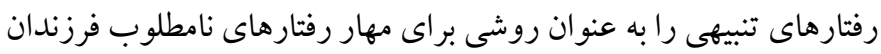

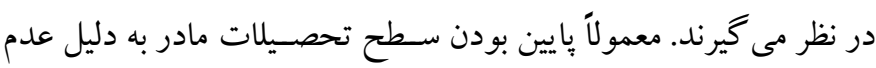

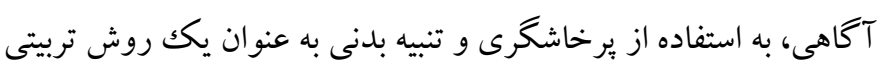

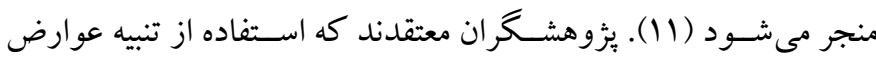

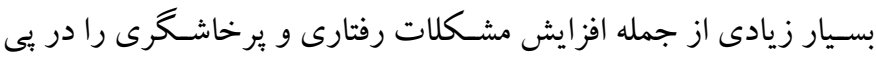

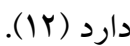

روى آوردها و مداخلات مختلفى جهت كاهش رفتارهاى تنبيهى ارائه

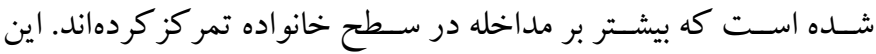

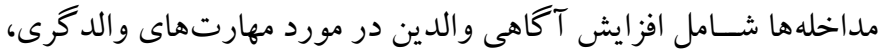

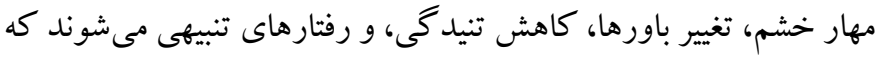

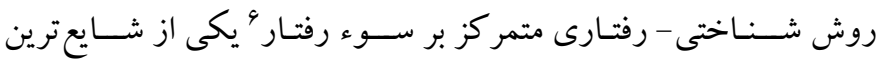

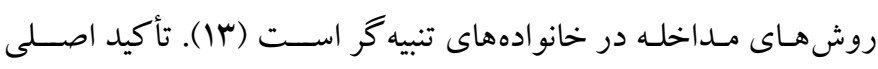

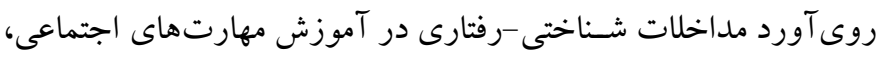

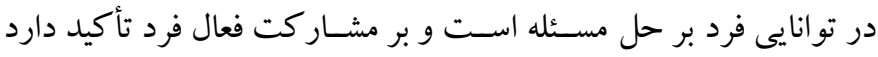

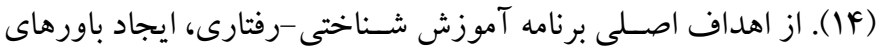
منطقى مبتنى بر تفكر، جـايكزينى افكـار منطقى و ســازش يـافته با افكار غيرمنطقى، بازسـازى شــناختى، مديريت خشـــه، و برنامهريزى فعاليتها (است (10 و 19) (19).

قدرتى، شريفى و عبدالهى (IV) در يثزوهشى نشان دادند كه آموزش

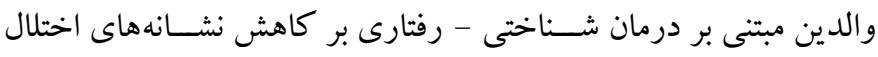

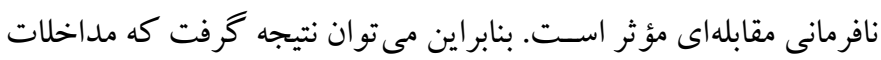

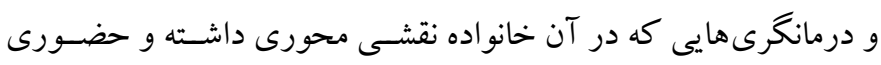
فعال در برنامههاى مداخلهاى داشته باشند، اثربخشى بالاترى دارند. معين

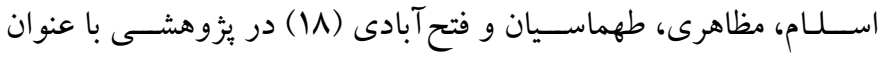

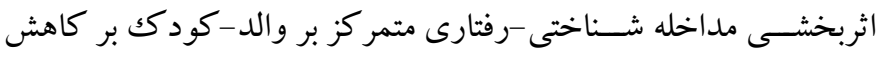

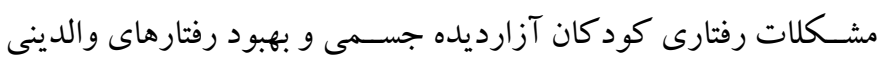
بدين نتيجه رسـيدند كه مداخله شــاختى -رفتارى در كاهش مشـكلات دروننمود و بروننمود، مؤثر اسـت. در زيرمقيـاسهاى رفتار والدين نيز

4. Lack of social maturity

5. Punishing behavior

6 . Abuse-focused cognitive-behavioral therapy مقلdo

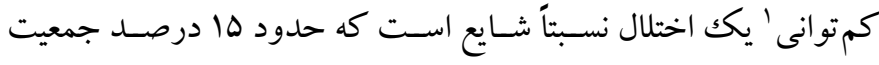

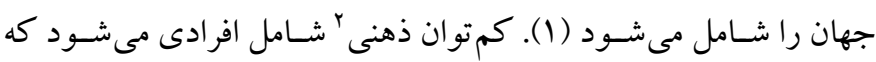

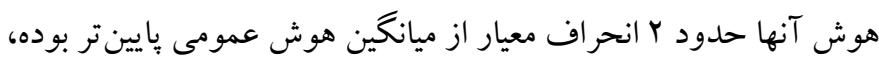
بسـيار آسـيب يُّير هسـتند، داراى نارسـايى در تحول ذهنى و همجنين

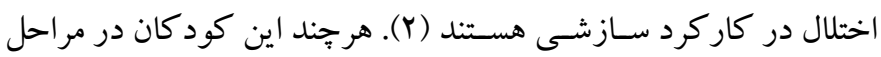

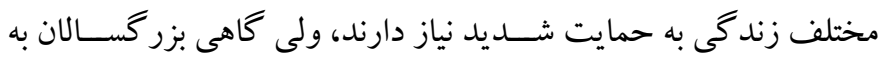

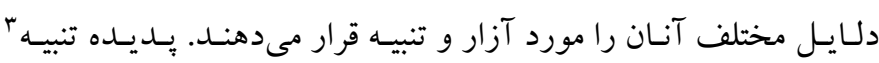

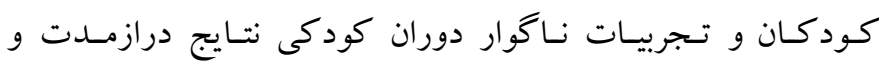
ناخوشايندى بر تحول و سازشيافتكى شخصيت در دوران بزر گسالى از

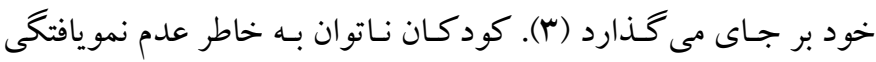

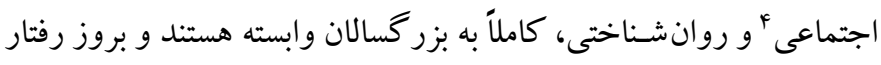
نامناسب به وسيله والدين و اعضاى خانو اده با كود كان ناتوان، با توجه به وله

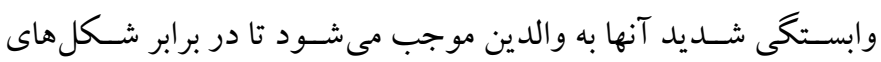
مختلف قربانى شدن، آسيبذيذيرتر از بقيه كود كان باشند (F). رفتارهاى تنبيهى ه شكل آشكار بدرفتارى با كودك است و جر احات برديه

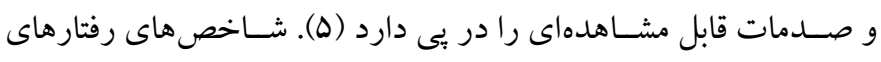
تنبيهى موارد مختلفى از قبيل تحقير، انتقاد دائمى، تهلديد، و كمبود عشـق و محبت را شامل مى شود (9). تنبيه شدن كود كان توسط مادر به ديد كاه مادر نسـبت به تنبيه، در كك مادر از شـدت اختلال تحولى كود كك و خشم

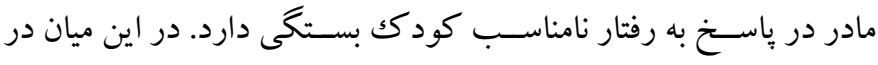

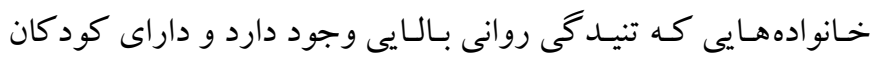

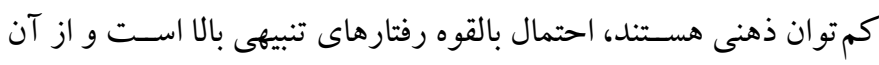

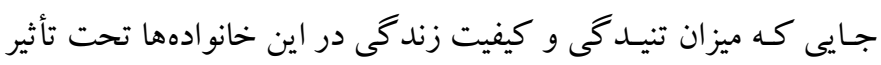

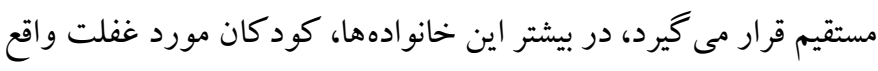

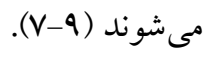

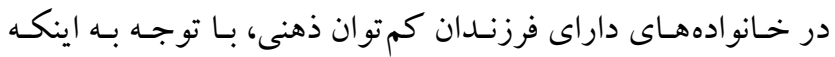

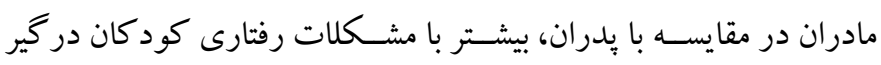

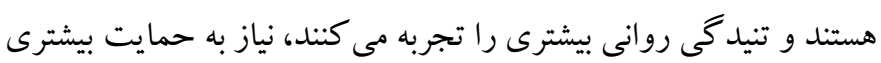

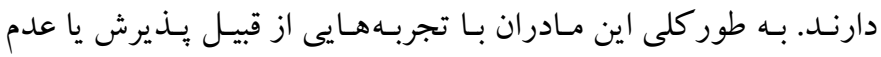

1. Disability

2. Intellectual disability

3. Punish 
بررسى اثربخشى آموزش برنامه شـناختى-رفتارى بر كاهش رفتارهاى تنبيهى مادران دانش آموزان كمتوان ذهنى مى باشند.

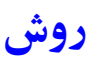

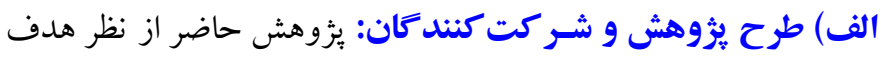

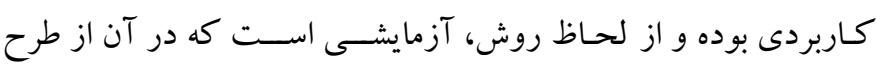

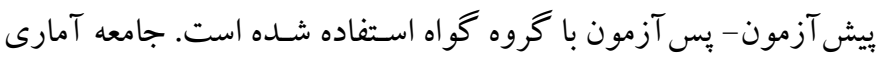

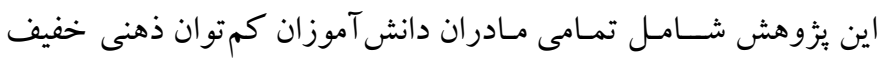

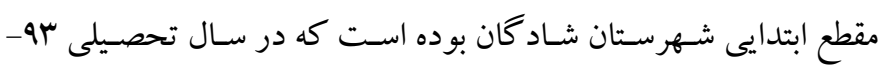

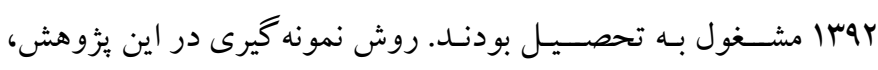
تصادفى ساده انجام شده است. به منظور انتخاب نمونه ابتدا ير سشنامه تنبيه

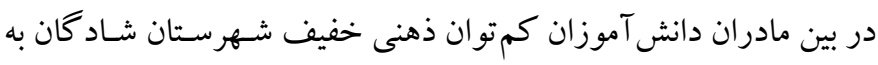

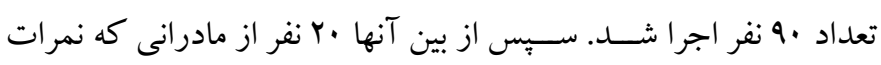

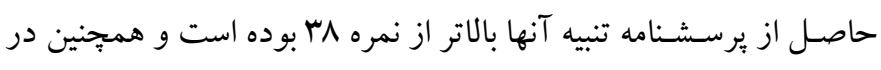

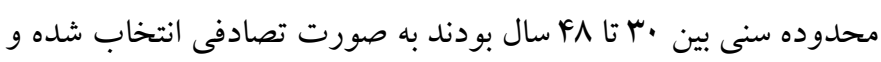

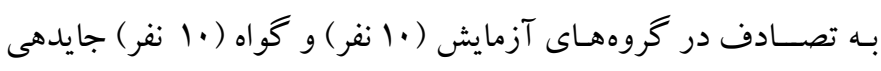

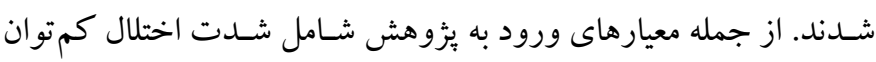

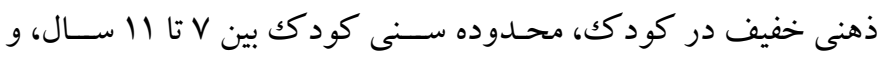

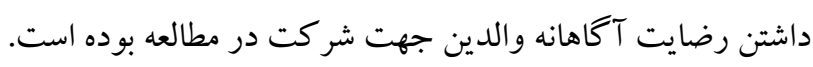

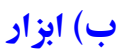

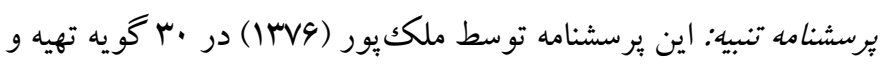

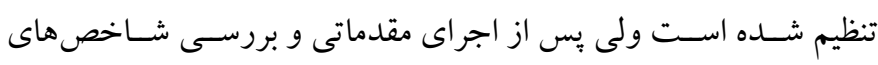

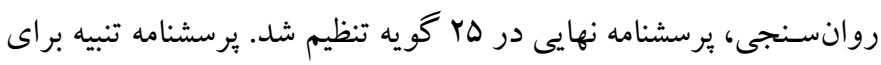

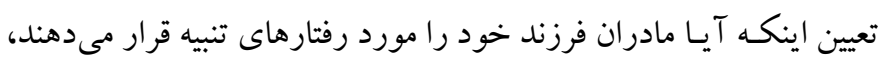

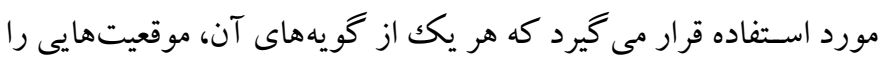

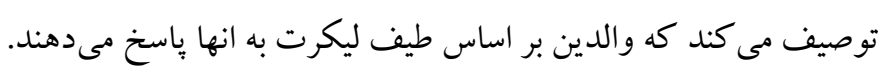

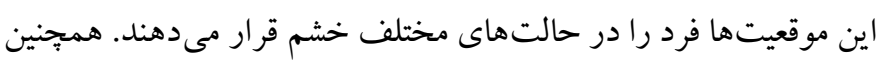

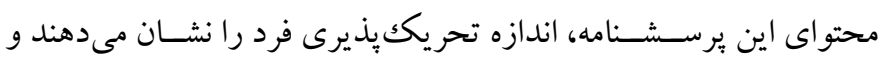

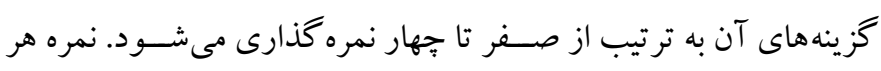

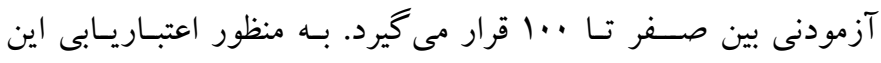

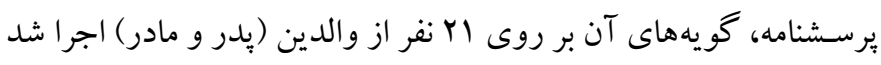

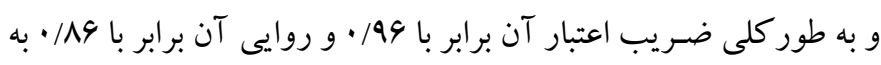

فقر نظارت و تنييه بدنى كاهش يافت، ولى ظرفيت كودككآزارى تغيير

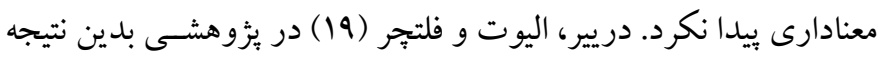
رسيدند كه آموزش مداخله شناختى -رفتارى با شيوه مهارت حل حل مسئله،

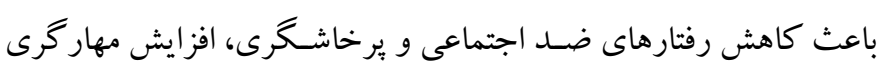

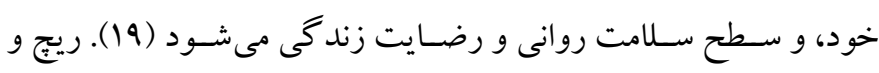

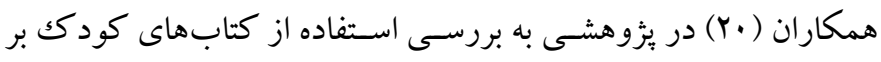

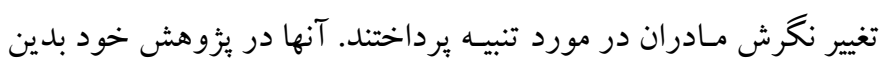

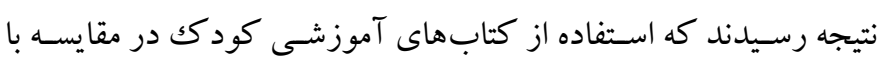

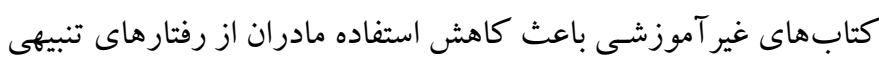

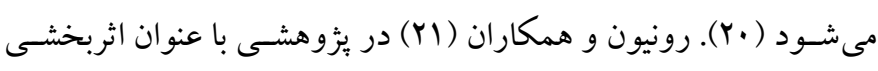

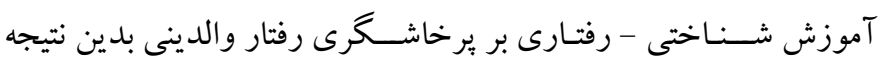

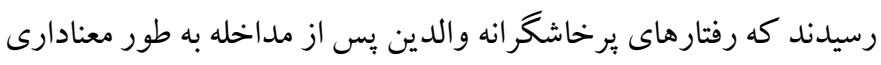

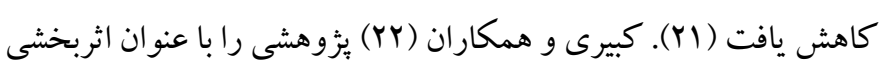

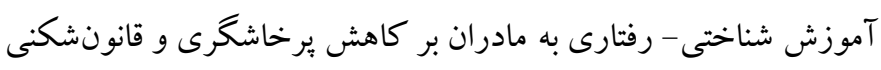

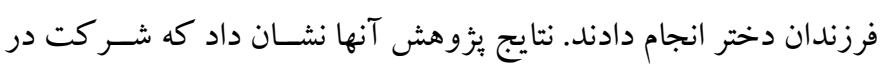

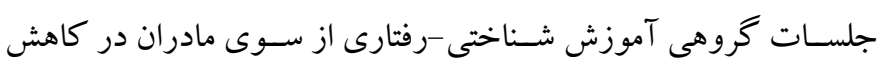

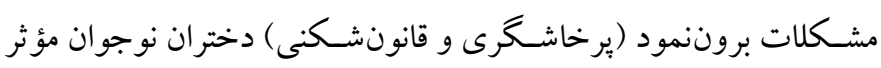

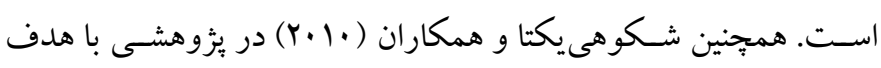

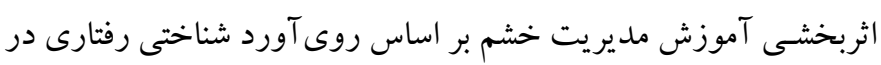

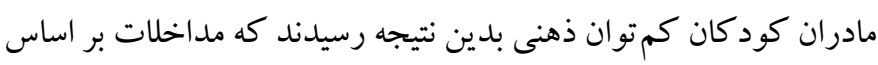

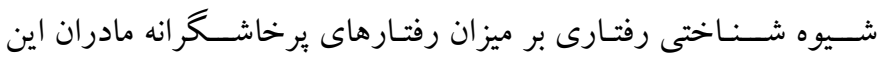

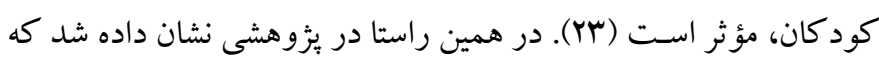

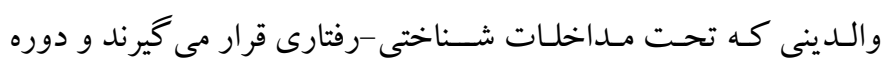

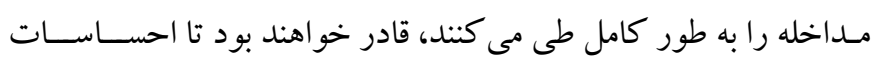

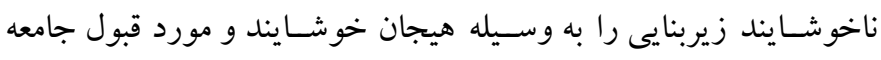

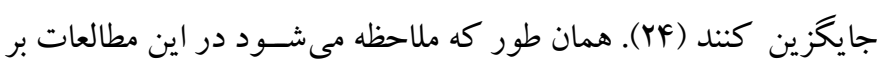

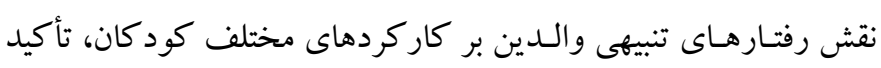

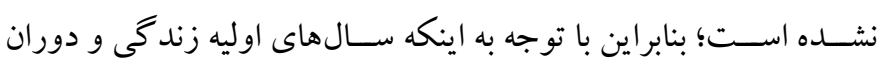

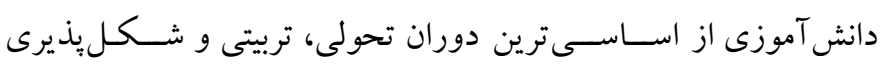

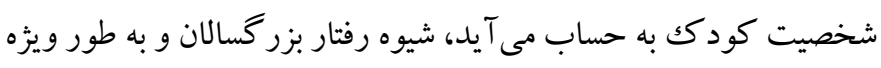

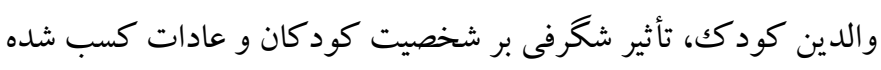

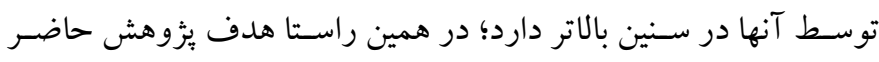


رفتـارى هـاوتن و كلـار كك' و شــــاختدرمانى و ئزوهش ايزدى فرد و

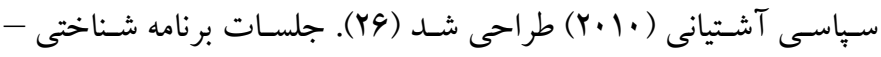

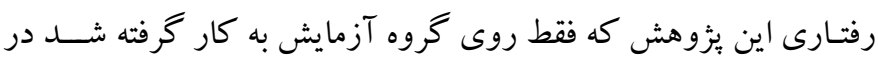
جدول ا توضيح داده شده است.
دسـت آمد (YO). در اين مطالعه نيز روايى يرسشــنامه توسط متخصصان

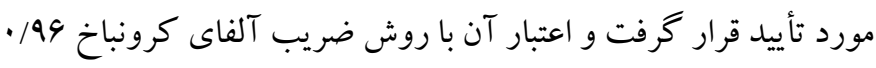

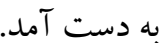
ج) معرفى برنامه مداخلهاى: برنامه شناختى - رفتارى به كار گرفته شده

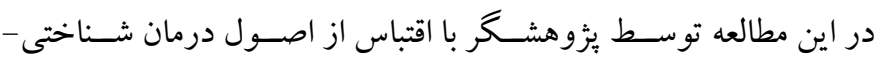

جدول 1: شرح جلسات كروهى آموزش برنامه شناختى- رفتارى

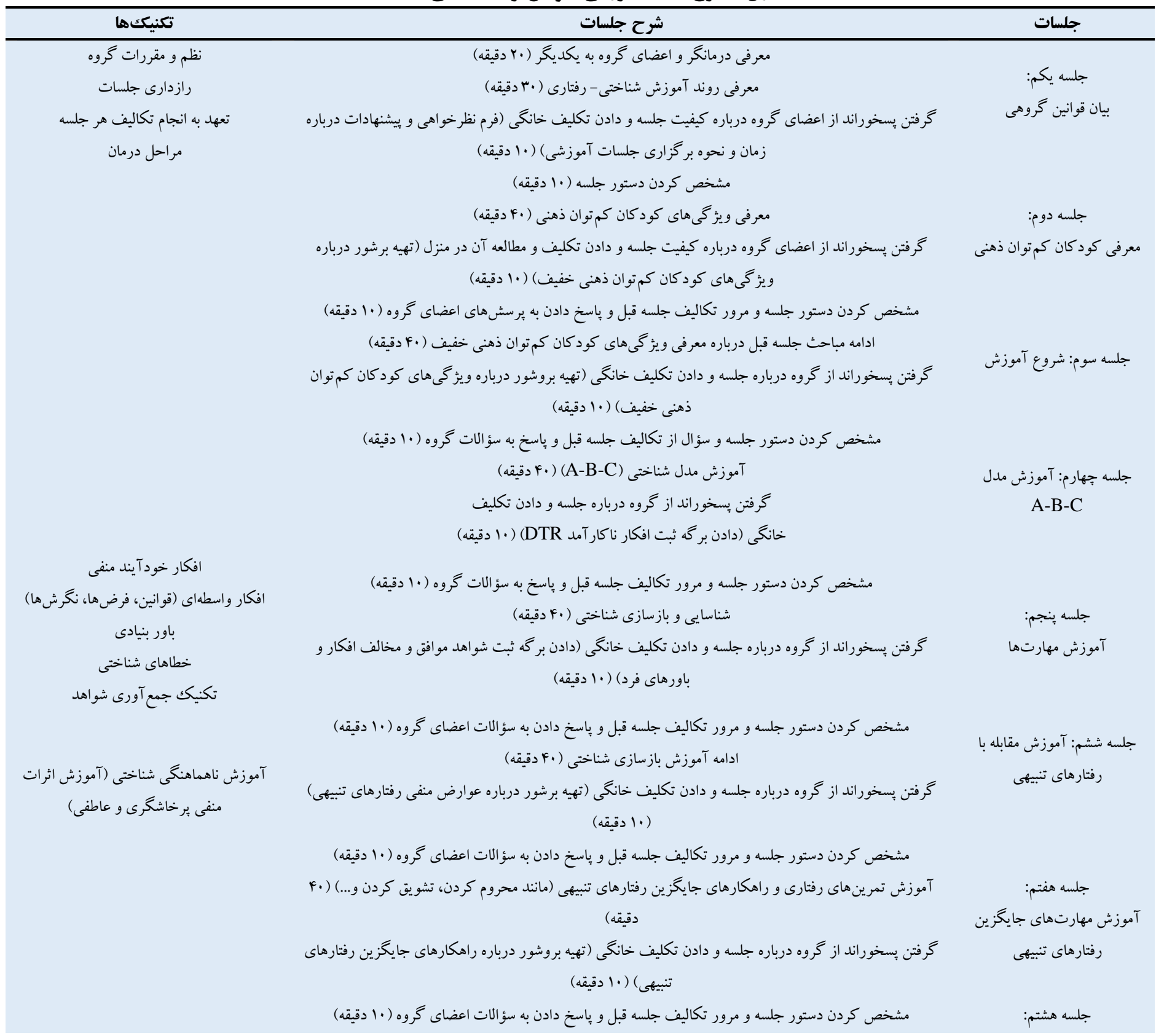

1. Haotoon and Kelark 


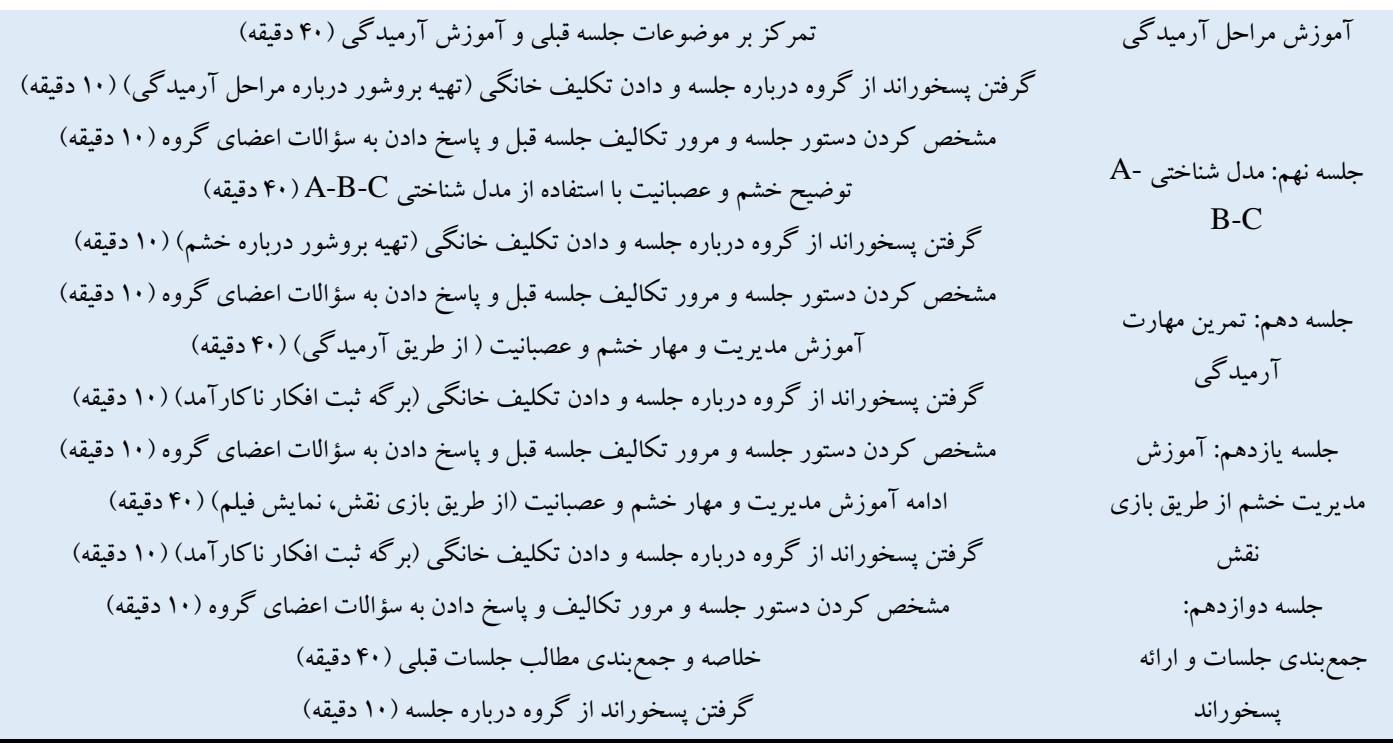

كَواه توزيع شـــ و دادهاى حاصـل از پس آزمون، مورد تجزيه و تحليل

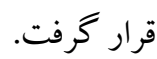

جهت تجزيه و تحليل يافتهاى بثزوهش از ميانگين و انحراف استـاندارد در سطح توصسيفى و از آزمون تحليل كوواريانس جهت مقايسه نمرات بيش آزمون و بس آزمون در سطح استباطى استفاده شد. تجزيه و تحليل

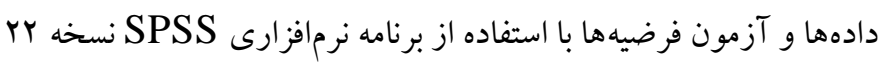

انجام شد.

يافتهها نتايج مربوط به ميانگين و انحر اف معيار نمرات بيش آزمون و بس آزمون دو گروه در جدول ب ارائه شده است.
د) روش اجر ا: براى اجراى اين بُزوهش ابتدا مجوزهاى للازم از دانشگاه

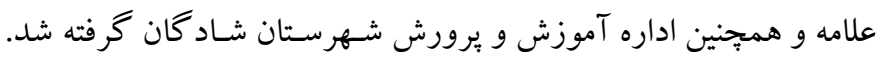
سبّ بر اساس شرحى كه در بخش روش اشاره شد، يرسشنامه تنبيه روى

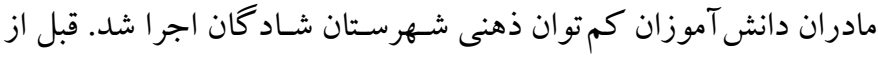

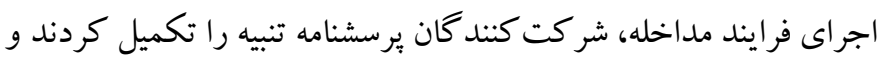

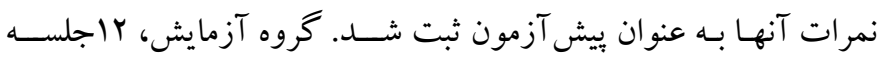

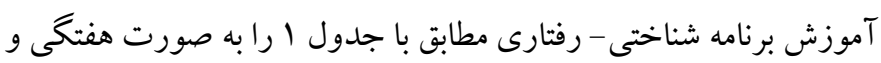
بـه مـدت Y جلســه .9 دقيقـهاى در هفته به مدت يكك ماه و نيم دريافت

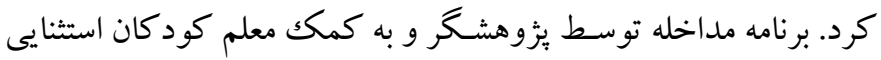

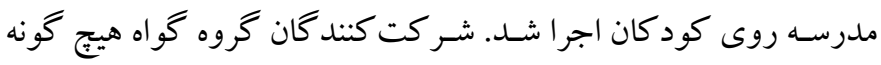

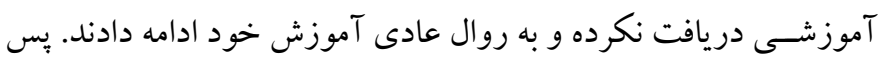

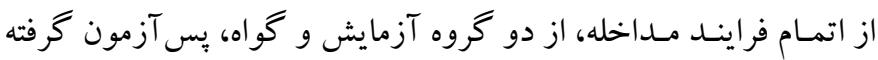

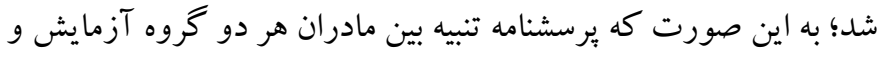

جدول r: آمارههاى توصيفى مربوط به برسشنامه تنبيه مادران

\begin{tabular}{|c|c|c|c|c|}
\hline انحراف استاندارد & ميانكين & تعداد & كروه & مرحله \\
\hline $1 \cdot / \Delta \Delta$ & $\Delta r / q$. & 1. & آزمايش & \multirow[b]{2}{*}{ ييش آزمون } \\
\hline $9 / 94$ & $49 / 1$. & 1. & كواه & \\
\hline$N / I r$ & $I V / r$. & 1. & آزمايش & \multirow[b]{2}{*}{ يس آزمون } \\
\hline$\Delta / \Delta q$ & $\mathrm{FV} / \mathrm{V}$. & 1. & كواه & \\
\hline
\end{tabular}


معنادارى دادها بالاى بنج صدم است؛ بنابر اين مىتوان كفت كه واريانس

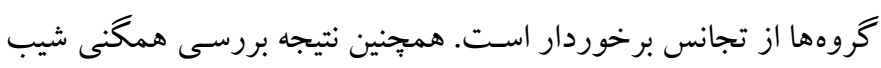

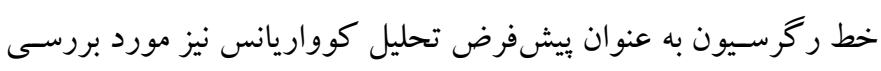

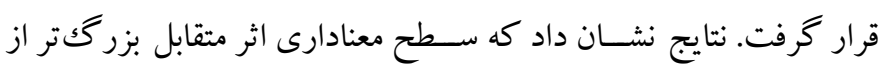

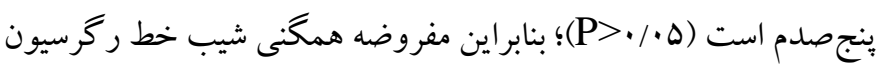

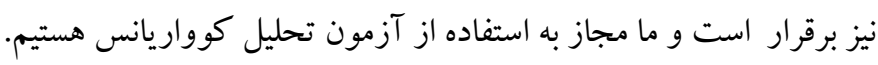

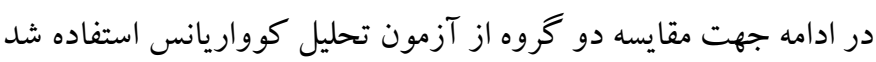
كه نتايج آن در جدول ب گزارش شده است.
همانطور كه در جدول r مشاهده مى شود گروه آزمايش و گگ اه در

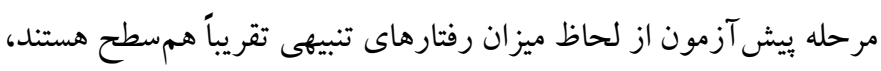

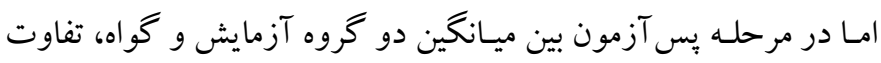

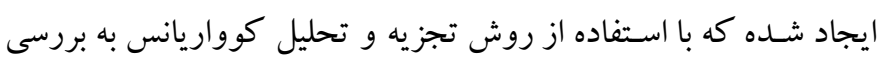
معنادار بودن اين تفاوت برداختهايم.

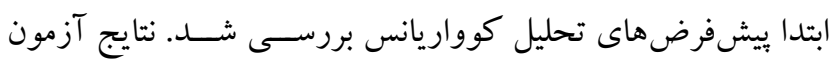

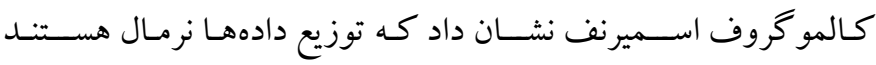

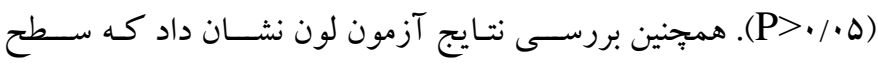

\section{جدول r. نتايج آزمون تحليل كوواريانس براى مقايسه ميزان رفتارهاى تنبيهى در كروههاى آزمايش و كواه}

\begin{tabular}{|c|c|c|c|c|c|c|}
\hline ضريب اتا & سطح معنادارى & $\mathbf{F}$ & ميانكين مجذورات & درجات آزادى & مجموع مجذورات & منبع تغييرات \\
\hline & $\cdot / \cdots$ & TVY/YOI & $r q \vee Q / \Lambda \cdot \Lambda$ & $r$ & $\Delta r \Delta Q / 9 / 9$ & مدل تصحيح شده \\
\hline.$/ \mathrm{rq}^{2}$ & $\cdot / 4 \cdot 1$ & - N $F Y$ & $V / r \cdot V$ & 1 & $V / r \cdot V$ & عرض از مبدأ \\
\hline . /rar & $\cdot \cdots$ & VI/990 & $V \cdot 1 / r 94$ & 1 & $V \cdot 1 / r 94$ & ييش آزمون \\
\hline \multirow[t]{4}{*}{$\cdot / 119$} & $\cdot / \cdots 1$ & $\Delta r q / \& q F$ & $\Delta r I \cdot / r Y F$ & 1 & $\Delta r I \cdot / r Y F$ & كروه \\
\hline & - & - & Q/AFT & IV & $19 \mathrm{~N} / \pi \mathrm{TH}$ & خطا \\
\hline & - & - & - & r. & $r q \Delta \Lambda \mathrm{V} / \ldots$ & كل \\
\hline & - & - & - & 19 & $\Delta \Delta r q / Q \Delta$. & كل تصحيح شده \\
\hline
\end{tabular}

بر درمان شناختى - رفتارى بر كاهش نشانه هاى اختلال نافرمانى مقابلهاى؛

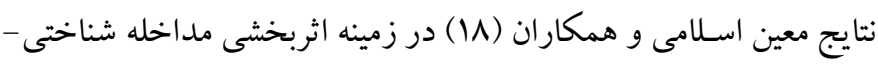

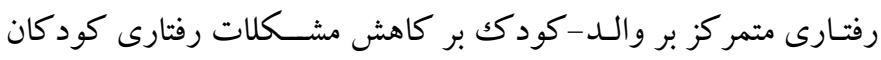

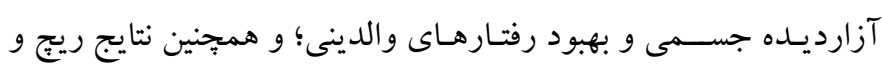

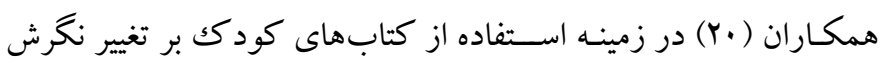

$$
\text { مادران در مورد تنبيه همسو است. }
$$

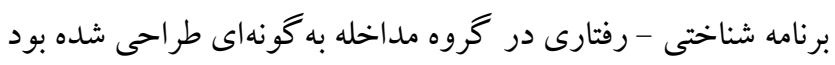

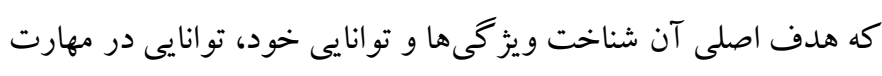

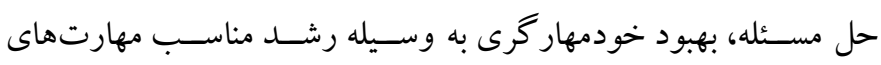

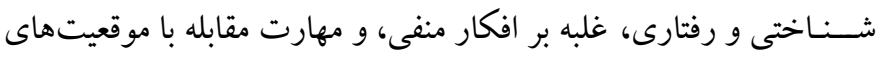

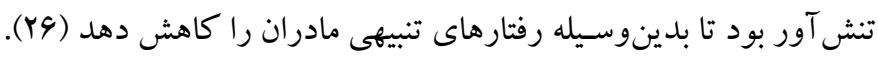

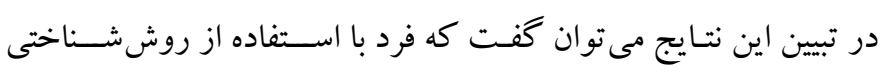

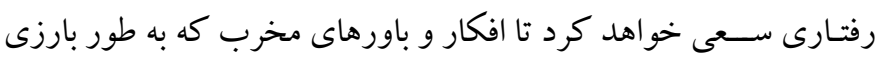

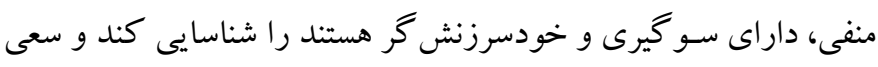

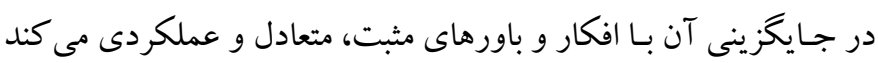

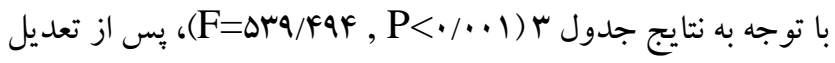

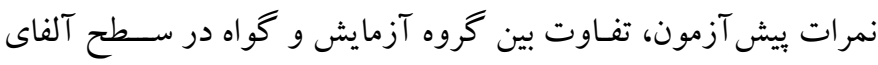

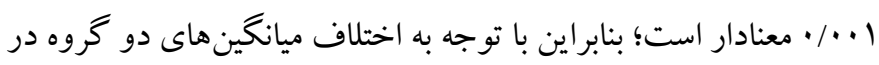

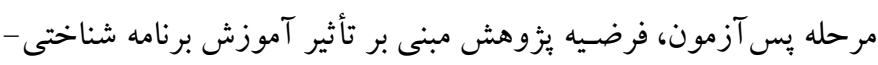

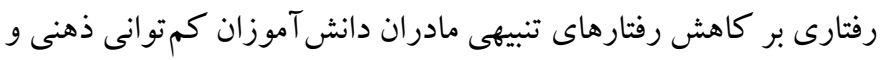

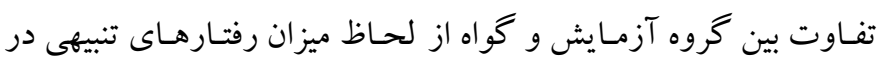
يس آزمون مورد تأييد قرار مى گيرد.

\section{بحث و نتيجه كيرى} هدف ئزوهش حاضـر، بررسى اثربخشى آموزش برنامه شناختى - رفتارى بركاهش رفتارهاى تنبيهى مادران دانش آموزان كمتو توان ذهنى بود. نتايج

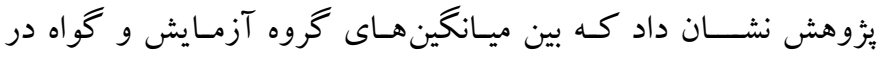

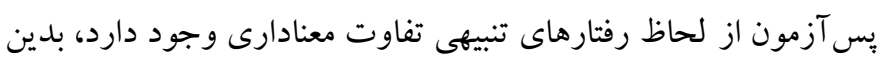

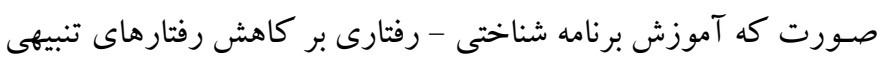

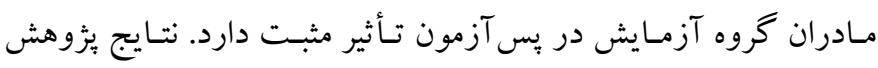

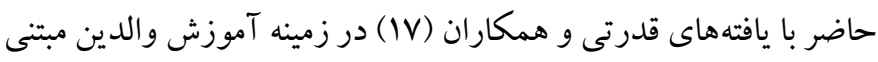


بود تا احساسات ناخوشايند زيربنايى را به وسيله هيجان خوشايند و مورد

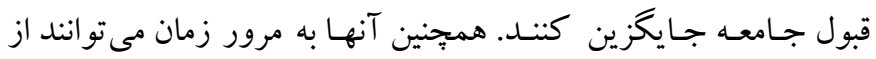

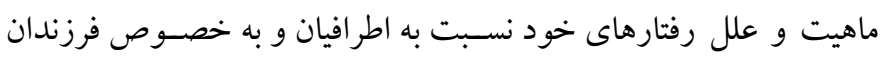

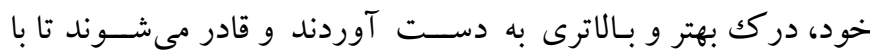
موقعيتهاى سـخت و طاقتفرسـا، شـيوههاى مناسبترى را به كار ببرند

هم:جنين در تبيين نتايج به دست آمده مى توان كفت كه در روى آورد

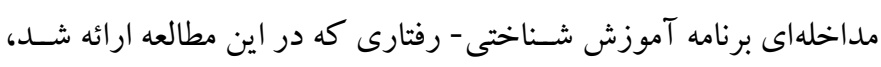

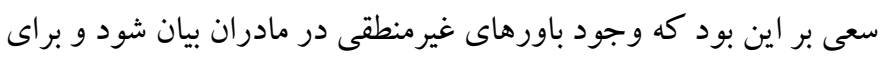

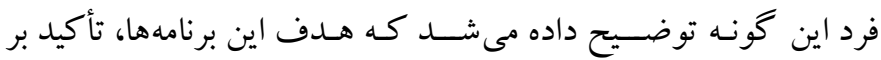
جايخز ينى باورهاى نادرست و غيرمنطقى با باورهاى منطقى و درست درد درد

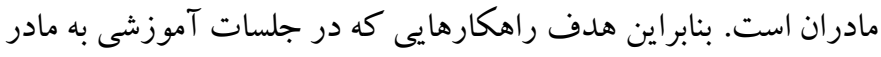

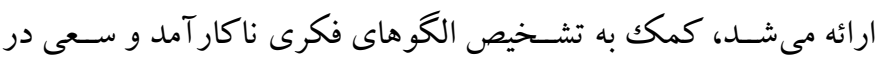

جايخزينى آن با الكوهاى فكرى كار آمد و صحيح بود.

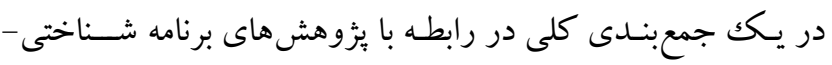

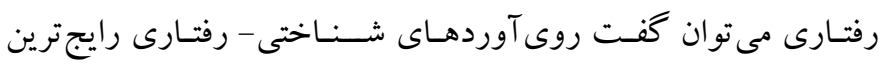

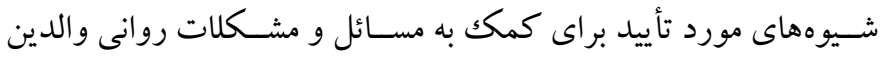

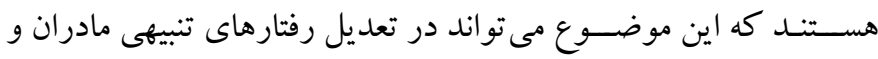
مهارت هاى مناسـب برورش كود كى و مهارگرى فردى، مؤثر واقع شود.

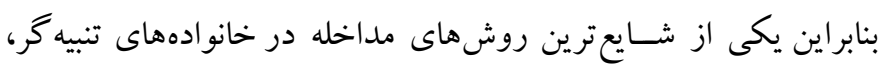

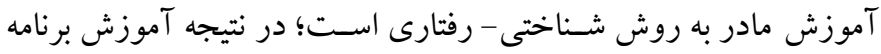

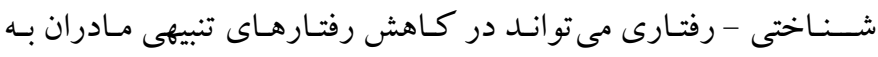

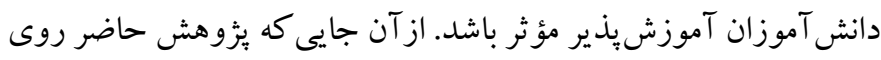

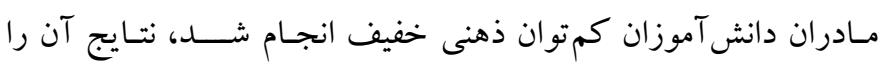

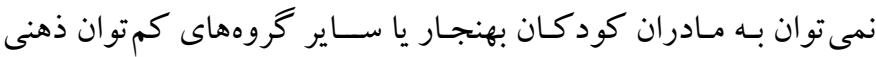

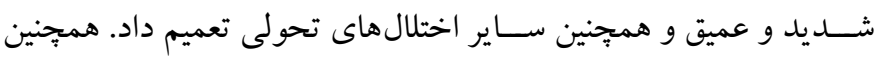

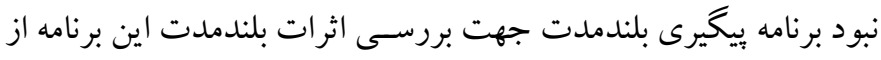

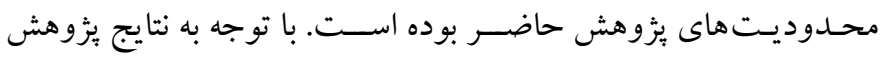

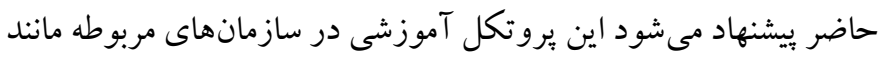

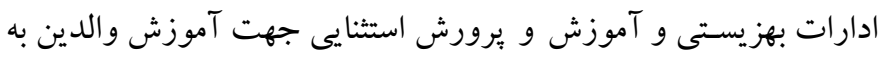
ويزه مادران داراى كود كان كم توان ذهنى مورد استفاده قرار گيرد. ايجاد

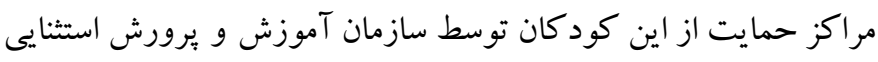

تا موجب بذيرش نقاط قوت و موفقيت شـود. همجِنين فرد با شــاسـايى كمبودهاى شـناختى و رفتارى و كسـبـ مهارتهاى جديد حل مســــله شناختى و روش هاى رفتار كردن، موجبات بهبود رفتارهاى خود رد را فراهم

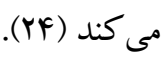
يافتهاى بزوهش حاضر با يافتهاى كبيرى و همكاران (Yr) مبنى بر

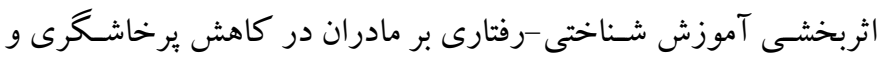

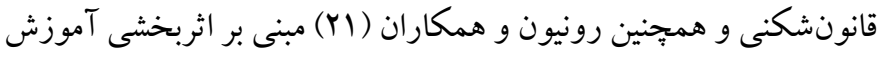

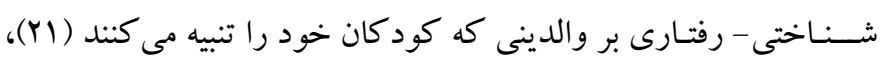

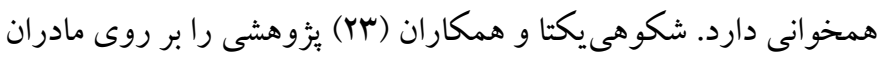

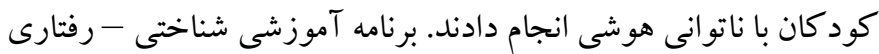

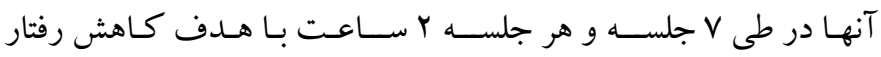

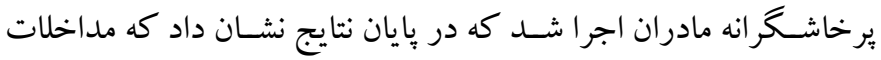

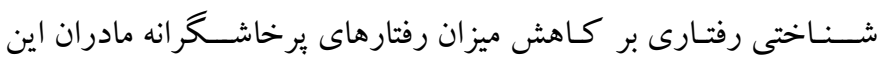
كود كان مؤثر اسـت. بايد توجه داشـت تفاوت اصلى در بزّوهش مذكور مئر

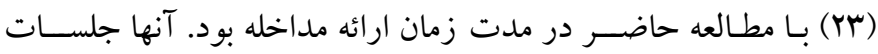

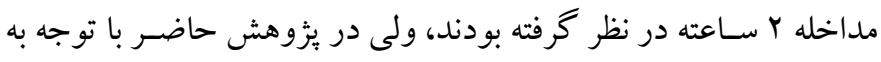

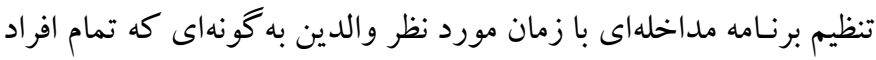

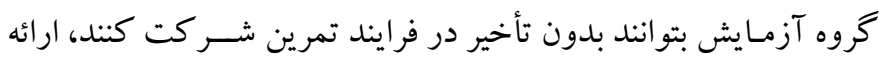
مداخله در طى با جلسه يكك ساعته در نظر گرفته شد.

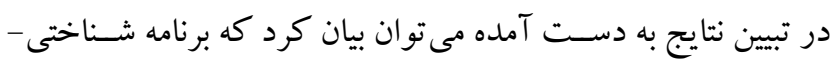

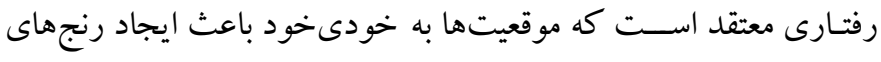
روانشناختى نمىشوند، بلكه جيزى كه اهميت دارد روشى است كه افراد

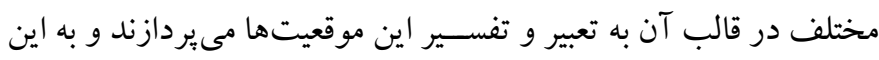

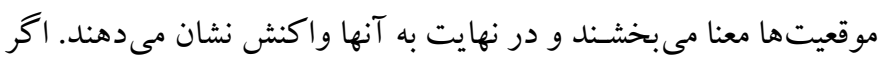
والـدين يـك موقعيت تنش آور خاص مانند داشــن كودك بـ با مشــكل

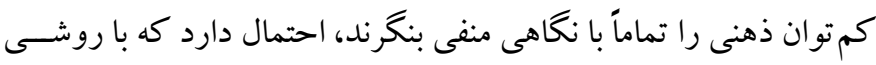

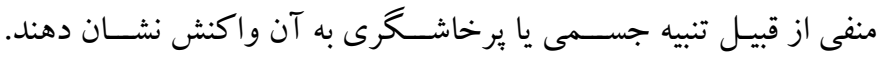
روش هاى مورد استفاده با توجه به مدل شناختى - رفتارى مى تو انند جنين بين

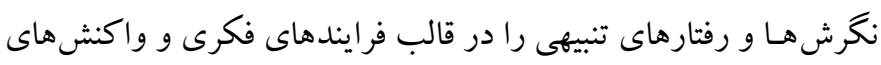
رفتارى، اصلاح كنند. مى توان انتظار داشت تا و الدينى كه تحت مداخلات شناختى -رفتارى قرار مى گيرند و دوره مداخله را به طور كامل طى مى كنند، قادر خو اهند 
نقش هر يك از نويسند كان: اين يُروهش بر كرفته از بايانامه كارشـناسى ارشد آقاى

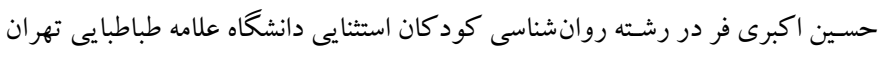

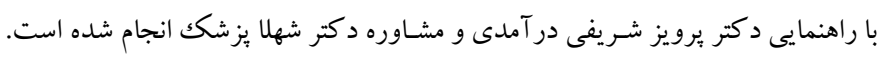

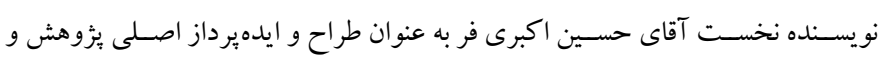

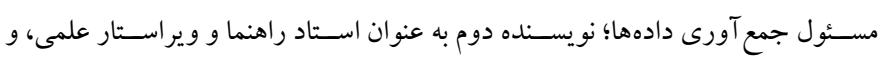

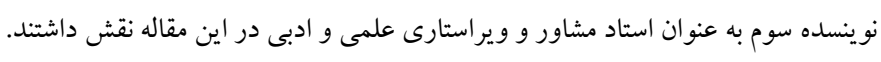

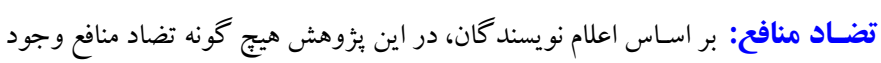

$$
\text { نداشته است. }
$$

تشكر و قدردانى: بدين وسيله از زحمات استادان محترم راهنما و مشاور اين بايانانامه،

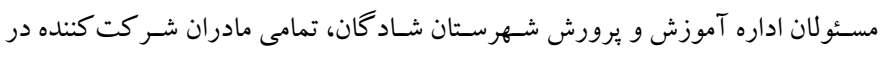

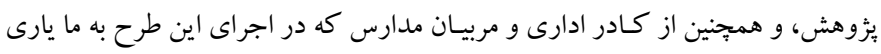

$$
\text { رساندند، تشكر و قدردانى مى وشود. }
$$

جهت بيشگيرى از رفتارهاى خشونت آميز و بالا بردن آكاهى والدين اين

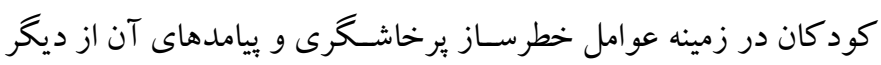
ييشنهادات اين يزوهش است. همجنين در سطح يُزوهشى ييشنهاد مى شود

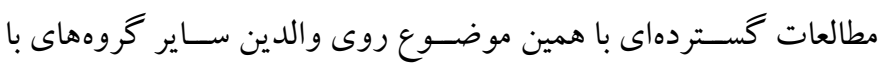

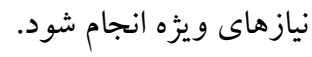

ملاحظات اخلاقى

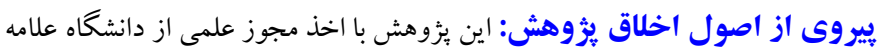

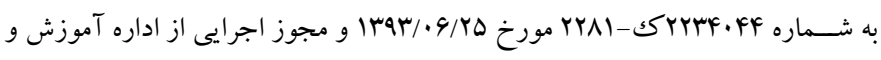

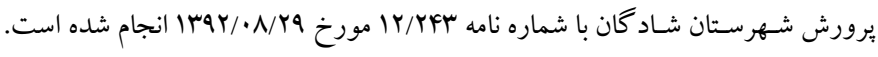

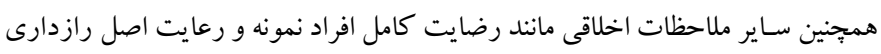

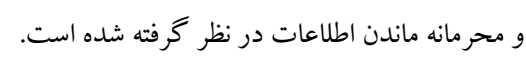

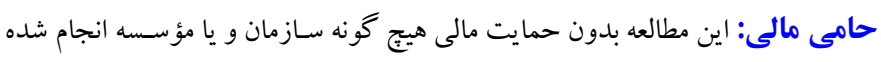
و بر خرفته از يايانامه كارشناسى ارشد است. 


\section{References}

1. Bazrafshan A, Hojati H. The effect of ROY adaptation theory on the resilience of mothers of children with intellectual disability in GonbadKavos city in 1396. Journal of Pediatric Nursing. 2019; 5(3): 1-7. [Persian]. [Link]

2. Matson JL, Boisjoli JA. The token economy for children with intellectual disability and/or autism: A review. Res Dev Disabil. 2009; 30(2): 240-248. [Link]

3. Anda RF, Felitti VJ, Bremner JD, Walker JD, Whitfield $\mathrm{Ch}$, Perry BD, et al. The enduring effects of abuse and related adverse experiences in childhood. Eur Arch Psychiatry Clin Neurosci. 2006; 256(3): 174-186. [Link]

4. Hibbard JH, Mahoney ER, Stock R, Tusler M. Do increases in patient activation result in improved selfmanagement behaviors? Health Serv Res. 2007; 42(4):1443-63. [Link]

5. Rebottini G. Won't you be my neighbor? Child abuse in a community context [Master's thesis]. [Pittsburgh, Pennsylvania, United States]: McAnulty College and Graduate School of Liberal Arts, Duquesne University; 2006, pp: 35-49. [Link]

6. Azarnioshan B, Beh-Pajooh A, Ghobary Bonab B. The effectiveness of cognitive behavior-based play therapy on the behavioral problems among primary students with intellectual disabilities. Journal of Exceptional Children. 2012; 12(2): 5-16. [Persian]. [Link]

7. Koydemir S, Tosun Ü. Impact of autistic children on the lives of mothers. Procedia Soc Behav Sci. 2009; 1(1): 2534-2540. [Link]

8. Peguero AA, Shekarkhar Z, Popp AM, Koo DJ. Punishing the children of immigrants: Race, ethnicity, generational status, student misbehavior, and school discipline. J Immigr Refug Stud. 2015; 13(2): 200220. [Link]

9. Schieve LA, Blumberg SJ, Rice C, Visser SN, Boyle C. The relationship between autism and parenting stress. Pediatrics. 2007; 119(Supplement 1): S114121. [Link]

10. Dihoff RE, Brosvic GM, Epstein ML, Cook MJ. Adjunctive role for immediate feedback in the acquisition and retention of mathematical fact series by elementary school students classified with mild mental retardation. Psychol Rec. 2005; 55(1): 39-66. [Link]

11. Park MS. The factors of child physical abuse in Korean immigrant families. Child Abuse Negl. 2001; 25(7): 945-958. [Link]
12. Qasemi F, Valizadeh F, Toulabi T, Saki M. A survey of some behavioral disorders due to parental corporal punishment in school age children. Yafte. 2008; 9(4): 59-65. [Persian]. [Link]

13. Kolko DJ. Individual cognitive behavioral treatment and family therapy for physically abused children and their offending parents: A comparison of clinical outcomes. Child Maltreat. 1996; 1(4): 322-342. [Link]

14. Seevers RL, Jones-Blank M. Exploring the effects of social skills training on social skill development on student behavior. National Forum of Special Education Journal. 2008; 19(1): 1-8. [Link]

15. Adavi A, Fathi Marghmalaki R, Madmoli Y, Madmoli M. Investigate the effectiveness of cognitivebehavioral stress management intervention on aggression in women with hypertension. Journal of Clinical Nursing and Midwifery. 2017; 6(1): 40-50. [Persian]. [Link]

16. Apidechkul T. Comparison of quality of life and mental health among elderly people in rural and suburban areas, Thailand. Southeast Asian J Trop Med Public Health. 2011; 42(5): 1282-1292. [Link]

17. Ghodrati M, Sharifi P, Abdollahi GH. The effect of Parental Management Training base on CognitiveBehavior Therapy on Children with Oppositional Defiant Disorder. Psychology of exceptional individual. 2015; 5(20): 109-123. [Persian]. [Link]

18. Moein Eslam M, Mazaheri MA, Tahmasian K, Fathabadi J. the efficacy of parent- child focused cognitive-behavioral intervention on behavioral problems of physically abused children and parental practices. Journal of development psychology. 2017; 13(50): 169-182. [Persian]. [Link]

19. Dreer LE, Elliott TR, Fletcher DC, Swanson M. Social problem-solving abilities and psychological adjustment of persons in low vision rehabilitation. Rehabil Psychol. 2005; 50(3): 232-238. [Link]

20. Reich SM, Penner EK, Duncan GJ, Auger A. Using baby books to change new mothers' attitudes about corporal punishment. Child Abuse Negl. 2012; 36(2): 108-117. [Link]

21. Runyon MK, Deblinger E, Ryan EE, Thakkar-Kolar R. An overview of child physical abuse: developing an integrated parent-child cognitive-behavioral treatment approach. Trauma Violence Abuse. 2004; 5(1): 65-85. [Link]

22. Kabiri M, Haghani Zemydani M, Khazan K, Shafiee $\mathrm{H}$. Effect of cognitive behavior therapy for mothers of aggressive daughters on aggression reduction among their daughters: a quasi-experimental study. Middle 
Eastern Journal of Disability Studies. 2017; 7(0): 80. [Persian]. [Link]

23. Shokoohi-Yekta M, Parand A, Zamani N. Anger management instruction for mothers: a cognitive behavioural approach. Procedia Soc Behav Sci. 2010; 5: 1371-1375. [Link]

24. Hofmann SG, Asnaani A, Vonk IJJ, Sawyer AT, Fang A. The efficacy of cognitive behavioral therapy: a review of meta-analyses. Cogn Ther Res. 2012; 36(5): 427-440. [Link]
25. Malekpour, M. The relationship between punishment and self-expression in children and adolescents. Quarterly Journal of Education. 1997; 50, 35-52. [Link]

26. Izadifard R, Sepasi Ashtiani M. Effectiveness of cognitive-behavioral therapy with problem solving skills training on reduction test anxiety symptoms. Journal of Behavioral Sciences (JBS). 2010; 4(1): 2327. [Persian]. [Link] 